\title{
INTENSIFICAÇÃO DO PROCESSO DE EXTRAÇÃO DE COMPOSTOS FENÓLICOS DO BAGAÇO DO MARACUJÁ AMARELO UTILIZANDO TECNOLOGIAS A ALTA PRESSÃO E ULTRASSOM
}

\section{Bruno Felipe de Paula Assis, Juliane Viganó, Grazielle N. Neves, Maria Angela de A. Meireles, Julian Martínez.}

\section{Resumo}

Este trabalho estudou a intensificação do processo de extração de compostos fenólicos do bagaço de maracujá amarelo utilizando tecnologias a alta pressão e ultrassom (US). O bagaço de maracujá desengordurado por extração com dioxido de carbono supercrítico foi utilizado na extração com líquido pressurizado (PLE) sob diferentes condições: sem ultrassom a $65{ }^{\circ} \mathrm{C}$ e $75^{\circ} \mathrm{C}$ e com ultrassom nas potências de $240 \mathrm{~W}, 440 \mathrm{~W}$ e $640 \mathrm{~W}$. Os extratos obtidos foram avaliados quanto ao teor de fenólicos totais, teor de piceatanol e capacidade antioxidante. A extração a $65{ }^{\circ} \mathrm{C}$ sem ultrassom e as utilizando ultrassom foram realizadas nas mesmas condições, porém o uso de ultrassom elevou a temperatura para $75^{\circ} \mathrm{C}$, promovendo assim maiores rendimentos. Para fins comparativos foi realizada a extração a 75 ${ }^{\circ} \mathrm{C}$ sem ultrassom, que apresentou maiores rendimentos do que os processos com ultrassom.

\section{Palavras-chave:}

Maracujá, extração, ultrassom.

\section{Introdução}

A extração com líquido pressurizado (PLE) é uma forma alternativa de extração e tem se mostrado bastante efetiva na extração dos fenólicos presentes no maracujá amarelo (Passiflora edulis) [1]. A PLE possibilita que o solvente permaneça no estado líquido mesmo acima da temperatura de ebulição devido à alta pressão. Ultrassom tem sido aplicado a processos de extração. As ondas ultrassônicas promovem ciclos de compressão e descompressão, gerando bolhas que crescem e explodem, em processo chamado cavitação, que pode levar ao rompimento de estruturas da amostra, liberando compostos de interesse e intensificando o rendimento do processo. $O$ objetivo deste trabalho foi intensificar a extração de compostos fenólicos do bagaço de maracujá amarelo por meio da PLE assistida por ultrassom.

\section{Resultados e Discussão}

As curvas cinéticas de conteúdo de fenólicos totais, teor de piceatanol e capacidade antioxidante estão apresentadas nas Figuras 1, 2 e 3, respectivamente.

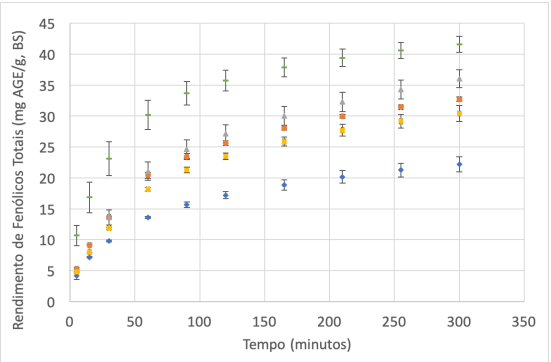

Figura 1. Rendimento de fenólicos totais na PLE de bagaço de maracujá.

As extrações assistidas por ultrassom foram realizadas nas mesmas condições que a PLE a $65^{\circ} \mathrm{C}$. No entanto, o ultrassom elevou a temperatura da extração para $75^{\circ} \mathrm{C}$. Consequentemente, a PLE assistida por ultrassom promoveu maiores rendimentos. Para fins de comparar os processos, foram realizadas extrações a $75^{\circ} \mathrm{C}$ sem US, que atingiram rendimentos superiores àqueles em que ultrassom foi aplicado. Os extratos mostraram capacidade antioxidante avaliada pelo método ferric reducing antioxidant power (FRAP).

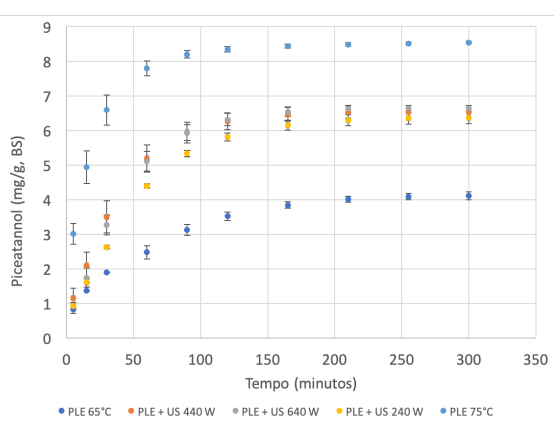

Figura 2. Rendimento de piceatanol na PLE de bagaço de maracujá.

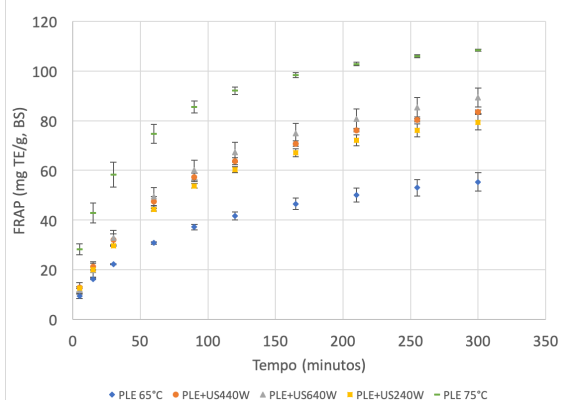

Figura 3. Capacidade antioxidante dos extratos PLE de bagaço de maracujá avaliada pelo método FRAP.

\section{Conclusões}

O uso de ultrassom permite intensificar o processo de extração com líquido pressurizado. Essa intensificação decorreu do aumento da temperatura causado pelo ultrassom.

\section{Agradecimentos}

À Unicamp e ao Programa Institucional de Bolsas de Iniciação Cientifica pela bolsa de iniciação científica e à FAPESP pelo auxílio financeiro (2017/23670-2).

[1] Viganó et al. Food Research International, v. 85, p. 51-58, 2016b. 